\title{
Satiety Role of the Small Intestine Examined in Sham-Feeding Rhesus Monkeys
}

\author{
James Gibbs, S. P. Maddison, and E. T. Rolls \\ University of Oxford, Oxford, England
}

\begin{abstract}
A sham-feeding preparation utilizing rhesus monkeys was employed to investigate the anatomical site of origin of satiety signals in the gastrointestinal tract. A series of experiments in which food was diverted from the stomach, the small intestine, or both demonstrated that (a) food acting at the pregastric level is not sufficient to produce normal-sized meals, (b) the accumulation of food in the small intestine is necessary to produce normal-sized meals, and (c) a potent preabsorptive or postabsorptive satiety signal originates at the intestınal level. This unidentified satiety signal is sufficient to elicit satiety, can be dissociated from gastric emptying, and does not require the presence of gastric distention to operate.
\end{abstract}

From 1797 to 1802, Jacob Helm treated a patient who had developed a gastric fistula. In the course of his treatment, he conducted what has become recognized as the first experiment in the history of medicine: Helm found that his patient could avoid hunger if she introduced small amounts of food through the fistula and directly into the stomach every $4 \mathrm{hr}$ (Helm, 1803, cited in Kisch, 1954). Thirty years later, William Beaumont reported similar observations in his classic study of Alexis St. Martin (Beaumont, 1833/1959).

These two early studies using the gastric load technique suggested that the critical events signaling satiety occurred at the level of the stomach or beyond and, thus, that stimulation of the pregastric gut by food was not crucial for satiety. Since the time of Helm and Beaumont, many studies have

Note This article was accepted by Editor-elect Richard F. Thompson.

This research was supported by the Medical Research Council of Great Britain, U.S. Public Health Service (National Institute of Mental Health and National Institute of Arthritis, Metabolism, and Digestive Diseases), the Royal Society of Medicıne Foundation, and the American Philosophical Society We thank G. P. Smith for helpful criticism of a prelimınary version of this manuscript.

S. P Maddison is now at the ARC Institute of Animal Physiology, Babraham, Cambridge, England.

Requests for reprints should be sent to James Gibbs, Edward W. Bourne Behavioral Research Laboratory, New York Hospital-Cornell Medical Center, 21 Bloomingdale Road, White Plains, New York 10605. employed the preloading technique to suggest that some signal from the stomach or intestine may play a role in producing satiety. A very large body of literature now demonstrates that preloading the stomach with food usually reduces subsequent food intake in humans and animals, depending upon the volume (Jordan, 1969) and time of preload (Baile, Zinn, \& Mayer, 1971; Quartermain, Kissileff, Shapiro, \& Miller, 1971). It should be noted that one important limitation of the gastric preload technique is that the effective site of action of the preload cannot be determined, because rapid gastric emptying of the usual liquid food load brings potential intestinal satiety mechanisms into play. The relative contributions of stomach and intestine to satiety are thus confounded unless precise parallel experiments measuring gastric emptying under identical conditions are carried out (McHugh \& Moran, 1979).

In studies using an intestinal preload strategy, several groups (e.g., Campbell \& Davis, 1974; Ehman, Albert, \& Jamieson, 1971; Hill, Ison, Jones, \& Archdeacon, 1952; Novin, Sanderson, \& VanderWeele, 1974; Snowdon, 1975) have found good evidence that duodenal or jejunal preloads of different types of food will reduce subsequent food intake in a variety of species. All of these studies are consistent with the existence of a postgastric satiety mechanism that is activated by the entry of food. Again, however, they are confounded by the problem mentioned above: Ingested food mixes with 
intestinally infused food as the ingested food empties from the stomach. Under these experimental conditions, the exact nature of the necessary and sufficient stimulus for intestinal satiety cannot be deduced. Furthermore, in this situation any contribution to satiety of food in the intestine is likely to be pharmacological and not physiological, since the duodenum is presented with more fluid under the test conditions than would normally occur. Finally, of course, ingested food activates potential gastric satiety mechanisms, and the relative contribution of these to satiety is unknown.

To circumvent some of these problems, we prepared rhesus monkeys with two chronic stainless steel cannulas, one situated in the stomach and the other in the first portion of the duodenum. By selectively using these cannulas for drainage or infusions of liquid food, we were able, in effect, to divide the upper gastrointestinal tract into compartments. With this strategy, we have begun to analyze the problem of which gut regions (pregastric, gastric, postgastric) are necessary and which are sufficient for satiety. Our results direct attention to the potency of satiety signals that arise at the level of the intestine.

\section{General Method}

\section{Subjects and Surgery}

Subjects were four male rhesus monkeys (Macaca mulatta) weighing between 3.1 and $4.2 \mathrm{~kg}$ Under sodium thopental anesthesia (initial dose, $5 \mathrm{mg} / \mathrm{kg}$ ), each monkey was equipped with a gastric and a duodenal cannula. Each cannula consisted of a stainless steel outer flange and shaft and a hard nylon inner flange and shaft.

By utılızing a purse string suture, the gastric cannula was sutured into the most dependent portion of the greater curvature $6 \mathrm{~cm}$ proximal to the pylorus; the duodenal cannula was similarly implanted $2 \mathrm{~cm}$ distal to the pyiorus The cannulas were exteriorized through the ventral surface of the abdomen, the gastric cannula to the left of midline and the duodenal cannula to the right During exteriorization, care was taken to avoid undue torsion or displacement of stomach or intestine. Each cannula was closed with a tightly fittıng stainless steel screw cap.

The animals were returned to their individual home cages and allowed at least 7 days to recover from sur. gery During this period, water and solid food (Dixons' diet, PFI) were freely avalable. In addition, fresh fruit (orange or banana slices) were offered several times per day. Cannulas were inspected and cleaned daily.
When each anımal was eating solid food eagerly and without difficulty, adaptation to the testing schedule was initiated

\section{Procedure}

All food was removed from the home cages at 1700 hours, and the monkeys were deprived of food over. night, water was freely available. At 1000 the next morning, each monkey was caught in its squeeze-back cage without anesthesia and placed in a primate re. strainıng chair. With experience, monkeys habituated to this procedure, and it could be carried out with a minimum of disturbance to the animal

The stainless steel caps were removed from the can. nulas Each cannula was flushed with pre-warmed (38 $\left.{ }^{\circ} \mathrm{C}\right) .15 \mathrm{M} \mathrm{NaCl}$ in sequential 5 -ml volumes until drainage was entirely clear; usually a total of $20-30 \mathrm{ml}$ was sufficient. A flexible, clear polyethylene drainage tube was attached to each cannula and situated so that it could not put any torsion on the cannula. The drannage tubes were initıally closed with a pinch clamp The monkeys were prevented from manipulating these tubes by a plastic divider attached to the primate re straining chair at the level of the diaphragm.

The primate chair was then placed inside a sound proof test cubicle $(1.7 \times .6 \mathrm{~m})$ The cubicle was vents. lated by a fan in the roof, which also served to mask anj extraneous noises in the testing room Illumination in the cubicle was provided by a strip light above and behind the monkey. The anumal was observed during the test through a one-way glass panel $(580 \times 270 \mathrm{~cm})$ in the door of the cubicle. Room lights were darkened to improve visibility of the animal. The two drainage tubes were passed through separate holes in the lower side walls of the cubicle and placed in graduated cylin ders, so that gastric and duodenal drainage could be measured if required for the particular experiment

The liquid food (chocolate-flavored Complan, the generous gift of Farley Health Products, Ltd., Plym outh, England) contained $22 \%$ protein, $21 \%$ fat, and $57{ }^{\circ}$ carbohydrate. It was prepared to a density of $1 \mathrm{kcal} / \mathrm{ml}$ by adding tap water and mixing in an electric blender Immediately before the beginning of the test. Liquid food was placed in an inverted $1,000-\mathrm{ml}$ graduated cylinder which was suspended outside the cubicle. The volume of liquid food in the cylinder could be easily read by the observer without disturbing the animal $A$ flexible polyethylene tube was attached to the cylinder. entered the cubicle through a hole in the upper side wall. and terminated in a ball-valve spout which was easily accessible to the monkey if it turned its head slightly to the left. An identical cylinder, tube, and spout appa ratus to the right provided tap water.

Throughout the 40 -min test, food intake, water intake, and (if required by the particular experiment) gastric or duodenal drainage rate were noted at $1 \cdot \mathrm{min}$ intervals. In addition, the behavior of each monkey was noted at $1-$ min intervals Behavioral observations were as follows. (a) feeding-suckıng or lıckıng food spout, (b) drinkıng - suckıng or lickıng water spout, (c) actıvity (non-ingestive)-any movement of the body, arms, hands, or eyes unrelated to feeding or drınkıng; and (d) restıng (i.e., apparent sleep)-no observable movements, and eyes closed or half closed. Special attention 
was directed toward the occurrence of any abnormal behavior, such as vocalization or unusual restlessness, which might indicate discomfort as a consequence of any experimental treatment.

At the conclusion of each test, the feeding and drunking spouts were removed, drainage tubes were disconnected, and the stainless steel screw caps were replaced to close the cannulas. Monkeys were returned to their home cages and provided with tap water and solid food until 1700 hours.

The order in which the experiments were performed varied among the four monkeys. Experiment 1 and Experiment 3 always preceded Experiment 4, but two monkeys underwent Experiment 1 (gastric cannula alone open) before Experiment 3 (duodenal cannula alone open) and two underwent these experiments in the reverse order. By this alternation. we hoped to detect any order effect on the efficiency of sham feeding between the two conditions

\section{Experiment 1}

In order to first establish the potency of pregastric (oropharyngeal and esophageal) food stimulation to produce satiety under these test conditions, this experiment compared liquid food intake when only the gastric cannula was open with liquid food intake under the control condition, in which both gastric and duodenal cannulas were closed.

\section{Method}

At least 3 control days (feeding with both gastric and duodenal drainage tubes clamped) preceded the first experimental day, on which the gastric drainage tube alone was unclamped. This procedure served to establish a stable baseline before any sham feeding occurred Subsequent test days alternated between the control (closed) condition and the sham-feeding (open) condition. In this experiment, the duodenal drainage tube remained clamped throughout all tests.

Each of the four monkeys was tested on at least two occasions with the gastric cannula open, except for Animal 18, which was tested only once; results on this one test, however, were typical of results from all other monkeys that underwent more than one test.

In sham-feeding tests, only those experiments in which the volume of drainage exceeded the volume of food intake were included in the data analysis. This conservative criterion was adopted as an indication that drainage from the cannula was complete and that no food was remaining within the gut to trigger satiety. The validity of this criterion was established by employıng a dry-weight method (Chaddock, Carlson, \& Hamilton, 1974). By this technique, duplicate 10-ml alıquots of recovered drainage samples were pıpetted, completely drıed $\left(72\right.$ hr at $\left.95^{\circ} \mathrm{C}\right)$, and weighed. Samples of food were similarly treated. By correcting for volume, the total weight of food ingested was compared with the total weight of drainage recovered, and equivalence of the two weights assured total recovery of ingested food.

\section{Results and Discussion}

The mean cumulative food intakes in the control (closed cannulas) and gastric shamfeeding conditions are shown in Figure 1.

When the gastric and duodenal cannulas were closed and liquid food was presented, the monkeys immediately began sucking the food spouts eagerly. After $5 \mathrm{~min}$, this initial phase of fast intake declined. By $10 \mathrm{~min}$, the monkeys had essentially stopped eating, having consumed at this point $85 \%$ of their intake for the entire test period. The monkeys characteristically groomed their arms and upper torsos briefly, visually explored the test cubicle, and then appeared to sleep. They would occasionally awaken during the test period, but eating, if it did occur, was confined to small, widely spaced bouts of $10-15 \mathrm{ml}$. These bouts were almost always taken in the form of licking, not by sucking, the food spout.

When the gastric cannulas were open, food intake and behavior were markedly altered. Sham feeding began at a rate that was not significantly different from the rate of feeding on days when the cannulas were closed (see Figure 1, at 5- and 10-min points), but this initial rapid rate of vigorous sham feeding continued until near the close of the test, when some tapering off was seen. By the end of the $40-$ min period, mean total sham intake was 2.9 times normal intake. When cannulas were open, monkeys occasionally stopped sham feeding, but those periods were of very brief duration (rarely more than $1 \mathrm{~min}$ ) before vigorous sham feeding was resumed.

Thus, on days when monkeys sham fed with gastric cannulas open, they ate almost continuously during the entire test period and consumed approximately three times their normal food intake. Satiety was absent-the animals never exhibited the usual sequence of satiety behaviors that occurred when gastric cannulas were closed. The appearance of the monkeys under the open cannula condition was striking in that they seemed "locked" to the food spout and the act of feeding, to the virtual exclusion of other behaviors.

These results mean that any oropharyngeal or esophageal signals (and their conditioned or unconditioned responses) that may 


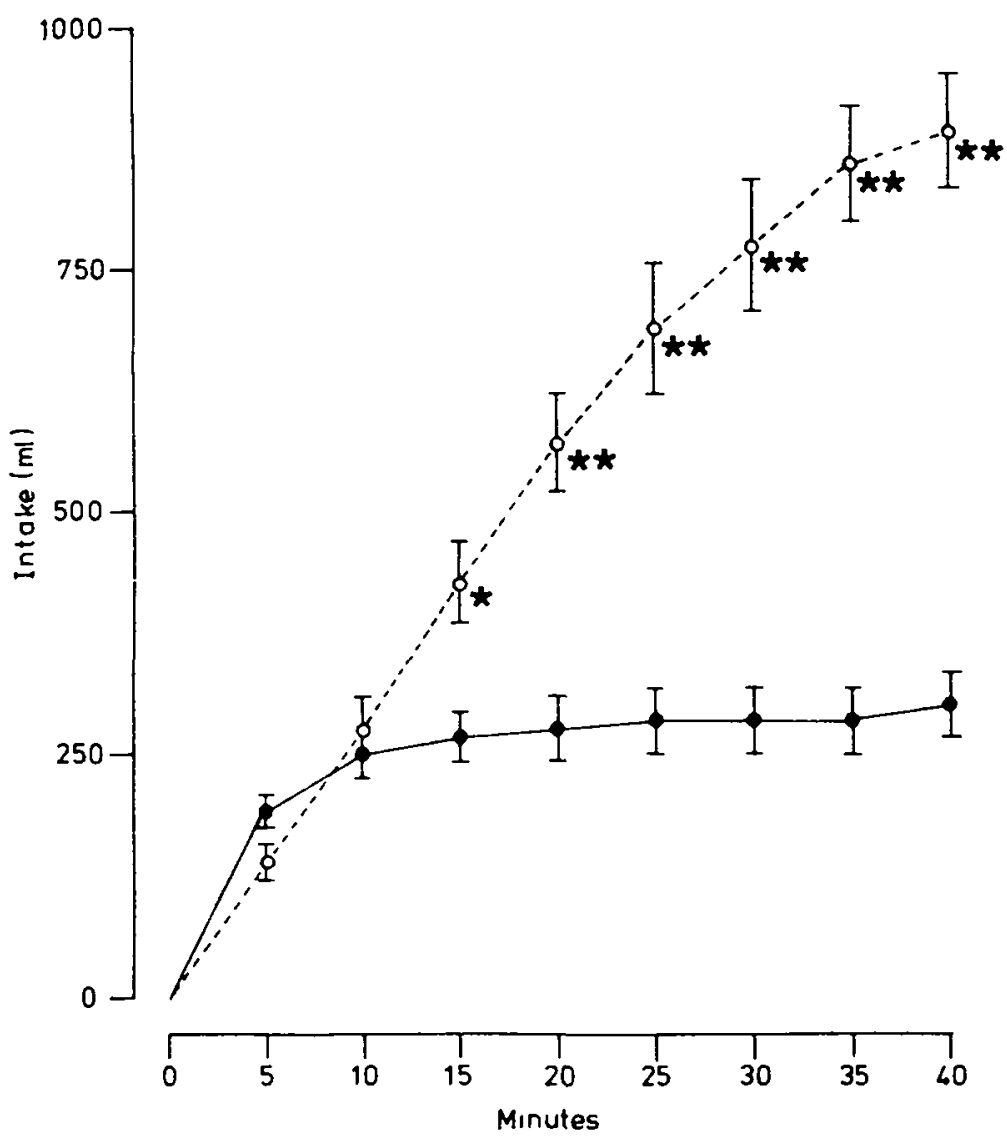

Figure 1 Cumulative $(M \pm S E)$ liquid food intake ( $1 \mathrm{n} \mathrm{ml}$ ) in four monkeys after overnight food deprivation when gastric and duodenal cannulas were closed (filled circles) and when gastric cannulas were open (open circles). (Statistically significant differences from closed cannulas condition: ${ }^{*} p$ $<.05,{ }^{* *} p<.01$, matched-paurs $t$ test, two-tailed.)

be generated under these conditions are not sufficient to stop feeding and elicit satiety. Therefore, the stomach and/or the small intestine is the site of origin of at least one satiety signal that is necessary for the control of test meal size at normal levels.

The results of this experiment confirm previous findings in rhesus monkeys under different conditions (Gibbs \& Falasco, 1978), and they are consistent with those of studies using several mammalian species which have demonstrated the weakness of pregastric food stimuli in producing satiety. Davis and Campbell (1973) and Young, Gibbs, Antin, Holt, and Smith (1974) found similar results in the rat. Janowitz and Grossman (1949) showed that esophagostomized dogs sham fed for much longer periods than they would normally feed. James (1963) studied sham feeding in one dog over a period of $2 \mathrm{yr}$ : throughout this period, sham feeding was greatly increased. The only report that conflicts with the several results noted above is that Hull and his colleagues (Hull, Livingston, Rouse, \& Barker, 1951): In repeated testing of a single dog, they found the gradual extinction of an initially vigorous sham-feeding response. This observation has not been replicated in any species, and we have not observed any lessening of sham feeding in rhesus monkeys that have been repeatedly and frequently tested over periods of a year (Gibbs \& Falasco, Note 1).

Finally, the complete failure of the pregastric gut surfaces to elicit normal satiety under these conditions in the rhesus monkey is reminiscent of the dramatic experimental hyperphagia reported in the blowfly. In this 
species, section of nerves that innervate the abdomen (recurrent nerve-Dethier \& Bodenstein, 1958, or ventral nerve trunkDethier \& Gelperin, 1967; Nuñez, 1964) may result in hyperphagia so uncontrolled that the fly will explode.

\section{Experiment 2}

The absence of normal satiety under the conditions of Experiment 1 indicates that some satiety signal from the level of stomach and/or small intestine is required for the production of normal-sized meals. If the small intestine is to be considered as a possible site of origin of food-elicited signals that act to end a meal, it must first be shown that food is in fact present in the small intestine when feeding stops at a test meal. In order to determine the distribution of food in the upper gastrointestinal tract at the moment of satiety, we performed radiological examinations of the upper abdomen on two rhesus monkeys after labeling their food with a radiopaque marker.

\section{Method}

Two monkeys were prepared for the radiological examinations by allowing them to eat their standard meal outside the usual test cubicle, with the X-ray unit
(Newton-Victor Mobile) and conventional screens and plates in place. During this test, gastric and duodenal drainage tubes were secured in place, but both remained clamped at all times; no drainage from the gastrointestinal tract took place. After 5-6 days in this situation, both monkeys were taking their standard-sized meals in a typically rapid fashion and then displaying the usual behavioral sequence of satiety, including grooming, visual exploration of the environment, and apparent sleep. A special effort was made to keep the darkened experimental room as quiet as possible, so that this behavioral sequence would not be interrupted. Meal size and behavior became quite regular during this 5 -day baseline period, and it was possible to predict with great accuracy when each monkey would end a meal.

Throughout this period, liquid food was prepared as usual, with the exception that a palatable commercial preparation of barium sulfate (Micropaque, Nicholas) was added in a volume of $10 \%$ of the total final food volume. This preparation was thoroughly mixed in an electric blender immediately before the beginning of each test.

When the baseline observations had stabilized, tests began. Each monkey had one control film taken of the abdomen immediately before food was presented, and a second film taken at the moment the test meal ended and the behavioral satiety sequence began. Films were made at an exposure time of .1 sec and setting of $75 \mathrm{~mA}$, $90 \mathrm{kV}$.

\section{Results and Discussion}

Representative films from one monkey (Animal 15) are displayed in Figure 2; identical results were obtained with Animal 18. It is clear that a large amount of radiopaque

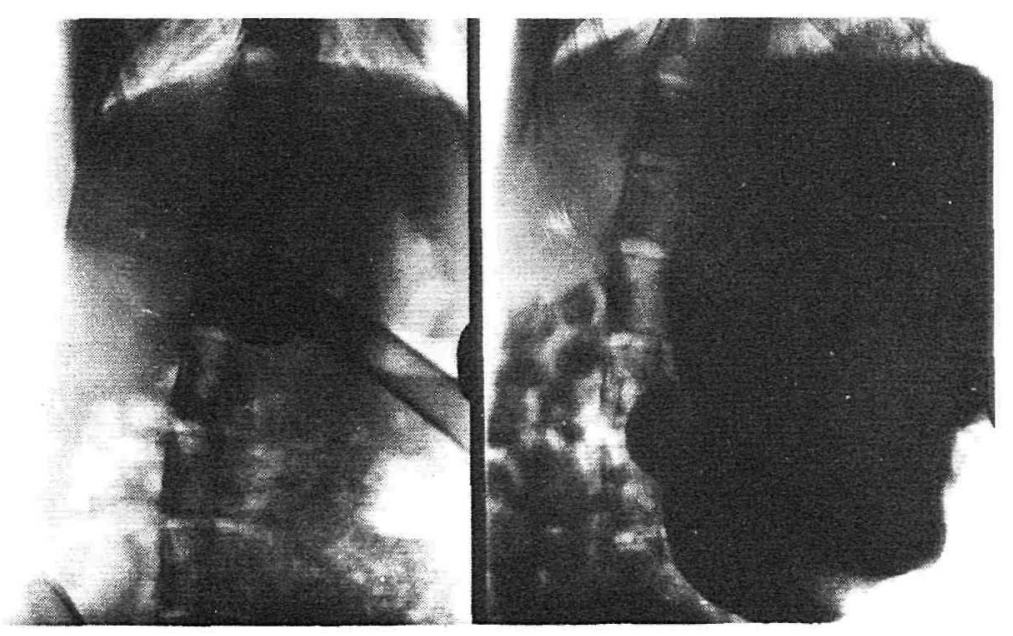

Figure 2. Radiological appearance of the upper gastrointestinal trace before feeding of a liquid test meal labeled with barium sulfate (left panel) and at the moment feeding stops (right panel). (During this test, gastric and duodenal drainage tubes were clamped. In the left panel, the edge of the gastric cannula is barely visible to the right, the duodenal cannula is in the center, and the duodenal drainage tube can be seen leading off to the animal's left. In the right panel, radiopaque material appears in the fundus and antrum of the stomach, and substantial amounts of the same material can be visualized in the first, second, and third portions of the duodenum.) 
material has penetrated well down the small intestine, being present in the first, second, and third portions of the duodenum at the time satiety occurs. Thus, under the present test conditions of diet and deprivation, the small intestine is clearly a candidate as a site of origin of unknown satiety signals. Figure 2 also demonstrates that this finding by no means rules out the possibility that the stomach makes a major contribution to satiety-note the large volume of radiopaque material filling the stomach.

The results of this experiment, showing a very rapid initial emptying of ingested material into the small intestine during normal feeding, are similar to the results of other studies in rhesus monkeys with less natural techniques for measuring gastric emptying. These studies showed that gastric preloads of water (Dubois, Natelson, van Eerdewegh, \& Gardner, 1977) or of liquid food (McHugh, Moran, \& Barton, 1975) begin to empty from the stomach during or within minutes of preload instillation. Our results in the rhesus monkey are consistent with previously reported results in humans that demonstrated an initial, extremely rapid phase of gastric emptying that takes place during and shortly after food intake. Using a radiographic technique similar to ours, Wilson, Dickson, and Singleton (1929) showed that a variety of ingested liquid substances, including fatty foods, enter the first portion of the small intestine during or immediately after the period during which the test substance is swallowed.

\section{Experiment 3}

What is the satiety role of food that enters the small intestine during feeding? In order to determine whether it was necessary for this food to accumulate in the small intestine, we attempted to produce sham feeding by allowing ingested food to drain from the open duodenal cannula.

\section{Method}

The procedure was similar to that for Experiment 1 The difference was that in the present experiment, the duodenal cannula remained open and the gastric cannula was closed This condition is referred to below as duodenal sham feeding
Drainage of ingested food from the duodenal cannula was never as successful or rapid as drainage from the gastric cannula had been in Experiment 1. Instead of obtaining a greater than $100 \%$ drainage to ingested volume ratıo, we obtained a mean drainage volume of $66 \%$ of ingested volume Several methods of low. pressure and intermittent suction, in addition to gravity drainage, failed to significantly enhance recovery. The difference between the drainage volume and the ingested volume was contained in the stomach in each monkey, since we collected this difference in additional drainage when the gastric cannula was opened at the end of the test Thus, removal of food from the small intestine via the duodenal cannula did not prevent the accumulation of some ingested food in the stomach

\section{Results and Discussion}

The mean cumulative food intakes in the control (both cannulas closed) and duodenal sham-feeding conditions are shown in Figure 3 . In spite of the relatively inefficient recovery of ingested food from the duodenal cannula, food intake and behavior were strikingly changed when this cannula was opened. Each monkey began sham feeding. at a rate that was not significantly different from the rate on the control day; however, in contrast to control intake, feeding continued throughout the entire test (Figure 3). Once again, as in Experiment 1, the behavioral sequence of satiety failed to appear, the animals appeared to be locked into feeding to the exclusion of other behavioral choices.

The results of this experiment demonstrate that ingested food must accumulate within the small intestine in order for meal size to be controlled at normal levels. When accumulation is reduced by duodenal drainage, food intake is doubled over a short test period.

It is important to note that this experiment does not elucidate the mechanism of hyperphagia under these conditions. It is not clear from these results that ingested food must accumulate and act directly within the small intestine to release an unknown satiety signal. Alternatively, the effect might be an indirect one-for example, it is likely that the rapid drainage of ingested food from the first portion of the duodenum in this experiment bypasses the normal intestinal brake on gastric emptying and therefore increases the rate of gastric emptying; the resulting reduction in gastric contents (and, for example, in gastric dis- 


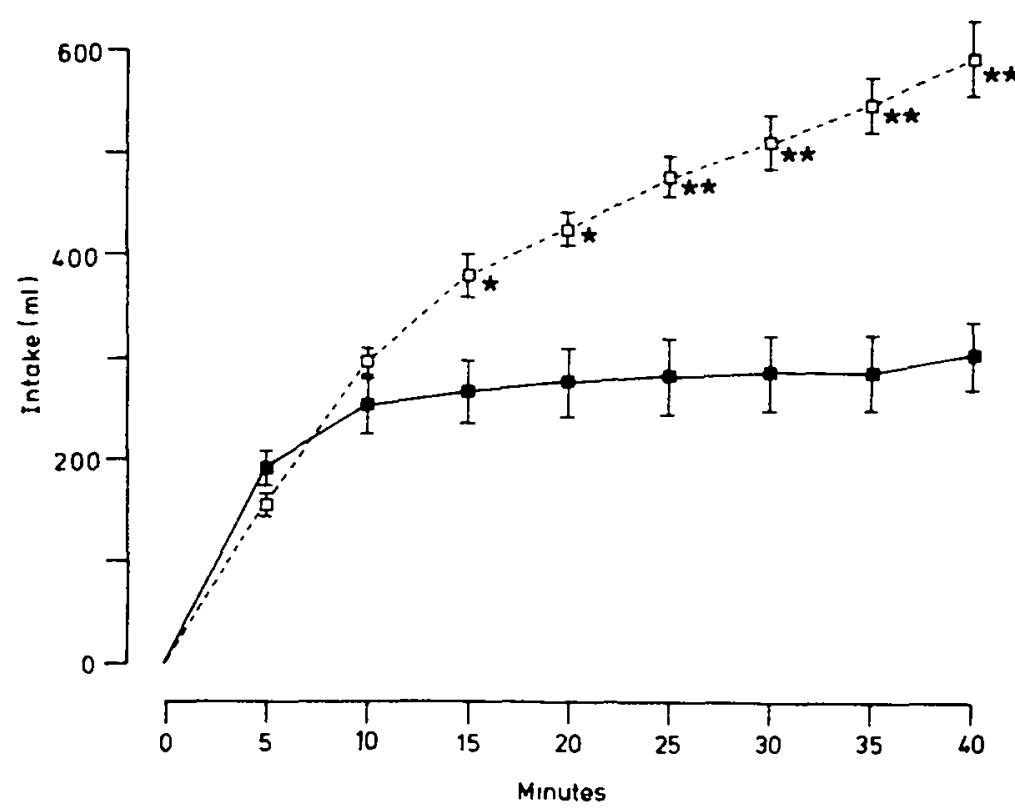

Figure 3 Cumulative $(M \pm S E)$ liquid food intake ( $\mathrm{n} \mathrm{ml})$ in four monkeys after overnight food deprivation when gastric and duodenal cannulas were closed (filled squares) and when duodenal cannulas were open (open squares). (Statistically significant differences from closed cannulas condition: ${ }^{*} p$ $<05,{ }^{* *} p<01$, matched-parrs $t$ test, two-tailed.)

tention) might neutralize a normally occurring gastric satiety signal.

A comparison of Figures 1 and 3 reveals that the extent of duodenal sham feeding is not so great as that of gastric sham feeding. At the close of the test period, total duodenal sham feeding was $596 \pm 36 \mathrm{ml}$ (mean \pm standard error), and total gastric sham feeding was $887 \pm 53 \mathrm{ml}$. The reason for this difference is not known, but the difference may represent the contribution of a satiety signal of gastric origin which is allowed to act to some degree when only duodenal cannulas are open. The results of this experiment in rhesus monkeys are consistent with results obtained in insects by Maddrell (1963); he demonstrated that a fistula placed in the midgut of Rhodnius produces a marked hyperphagia.

\section{Experiment 4}

Experiment 3 demonstrated that food must accumulate in the small intestine in order for meal size to be controlled at normal levels, but it left the mechanism of this effect unresolved. One method to explore this question further is to stimulate the small intestine directly by infusing food into the intestine via the duodenal cannula. The satiety effects of such infusions can be isolated by giving the infusions while monkeys are sham feeding with open gastric cannulas-recall from Experiment 1 that gastric sham feeding is continuous throughout the test period. Furthermore, under these conditions, one can study the possible satiety effects of duodenal infusions in a situation in which gastric distention cannot occur, since the gastric cannulas are open.

\section{Method}

Before continuing the test series with this exper1ment, each monkey was again given $3-4$ days of control tests during which gastric sham feeding took place with no duodenal infusions Infusions were carried out by delivering directly into the small intestine via the duodenal cannula elther the same kind of liquid food preparation that the monkeys were sham feeding or an equivolumetric control of $.15 \mathrm{M} \mathrm{NaCl}$ Liquid food or saline was pre-warmed to $38^{\circ} \mathrm{C}$ and maintained at this temperature and delivered by hand at rates of either 5 or $75 \mathrm{ml} / \mathrm{mm}$, by using $20-\mathrm{ml}$ syringes and a stopwatch.

These infusion rates were chosen after a series of prelımınary tests to determine whether, and at what infusion rate, reflux across the pylorus and into the stomach occurred. A few drops of dark food coloring 
sufficed to deeply stain the liquid food used in the intestınal ınfusion; if reflux occurred across the pylorus, the colored food could easily be identufied as it drained from the gastric cannula Using this method, we found that duodenal infusion rates in excess of $10 \mathrm{ml} / \mathrm{min}$ were occasionally and unpredictably accompanied by reflux into the stomach. Therefore, the maximum duodenal infusion rate employed in this experiment was 7.5 $\mathrm{ml} / \mathrm{min}$. In every test, food coloring was added to the liquid food or to the saline in order to identify any test in which reflux occurred, but, as anticipated, this never occurred at the low infusion rates employed.

Each monkey received an infusion of 20,40 , or $60 \mathrm{ml}$ of hquid food or an equivolumetric control of $.15 \mathrm{M}$ $\mathrm{NaCl}$ In the case of Anımal $15,37.5 \mathrm{ml}$ of liquid food was delivered at a rate of $7.5 \mathrm{ml} / \mathrm{min}$ instead of $40 \mathrm{ml}$ at a rate of $5 \mathrm{ml} / \mathrm{min}$, which each of the other three monkeys recelved. As seen below, however, this slight variation at this dose made no difference in the general result obtained in this animal Each food infusion and the control were given once to each monkey in a random order, and the order of infusions was randomly varied between animals. Infusions always began at the moment when the food spout was presented

\section{Results and Discussion}

The effect of the 40-ml infusion for each of the four monkeys is illustrated in Figure 4. The control infusion of physiological saline into the duodenum produced little or no suppression of sham feeding: A comparison of Figures 1 and 4 shows that sham feeding was at least as rapid in the present experiment as in Experiment 1. In contrast, the infusion of equivolumetric food into the small intestine resulted in a cessation of sham feeding in every monkey. The dura-

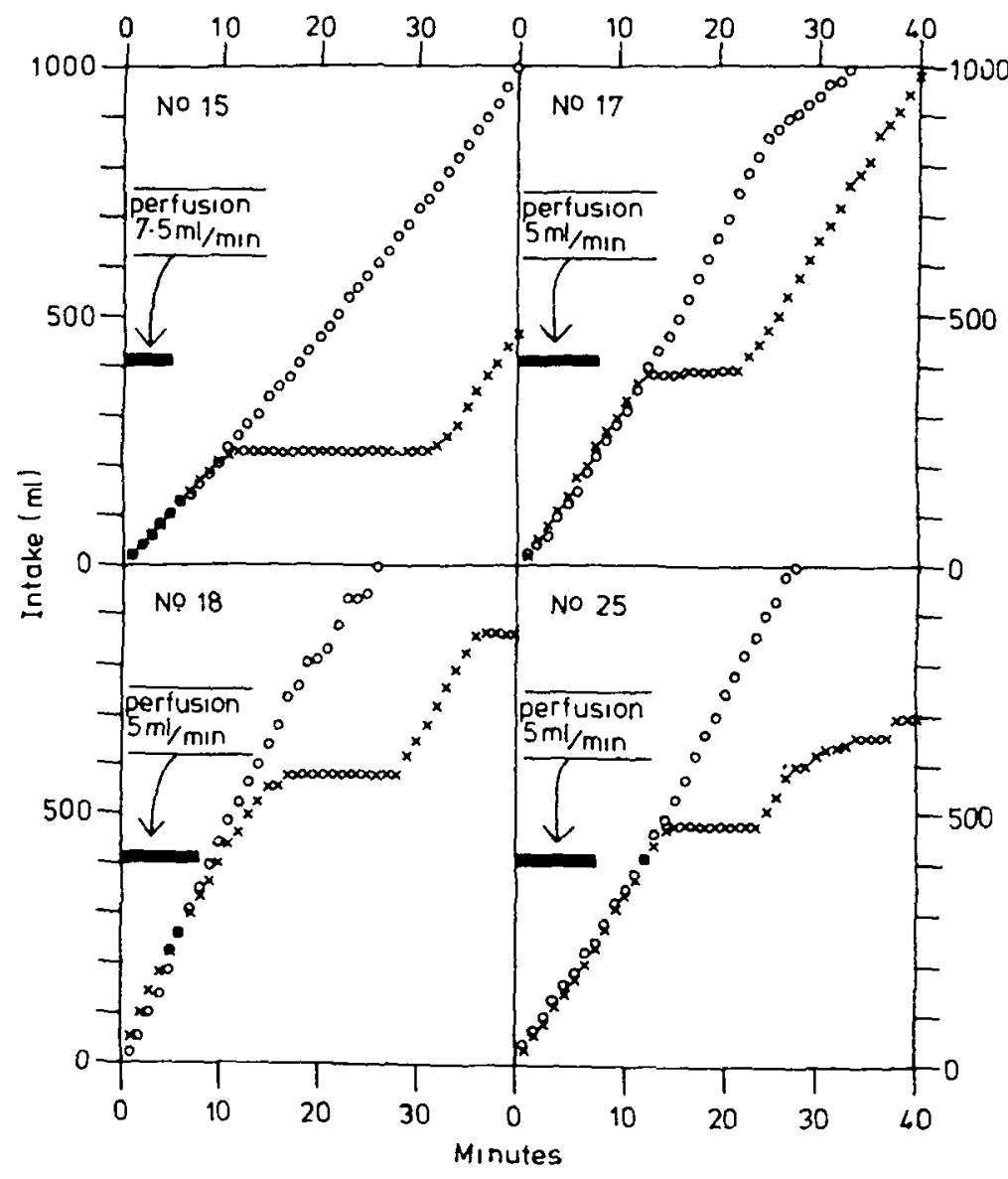

Figure 4. Curnulative liquid food intake in each monkey at 1 -min intervals when gastric cannulas were open (Circles indicate intake when .15 M NaCl was infused into the small intestine through the duodenal cannulas; crosses indicate intake when liquid food was infused. The total amount of infusate was $40 \mathrm{ml}[5 \mathrm{ml} / \mathrm{min}$ for $8 \mathrm{~min}$ ] in each monkey except Anımal 15, in which the total was $375 \mathrm{ml}$ [7 5 $\mathrm{ml} / \mathrm{min}$ for $5 \mathrm{~min}\}$. The bar beginning at $0 \mathrm{~min}$ indicates the duration of the intestinal infusion in each
animal.) 


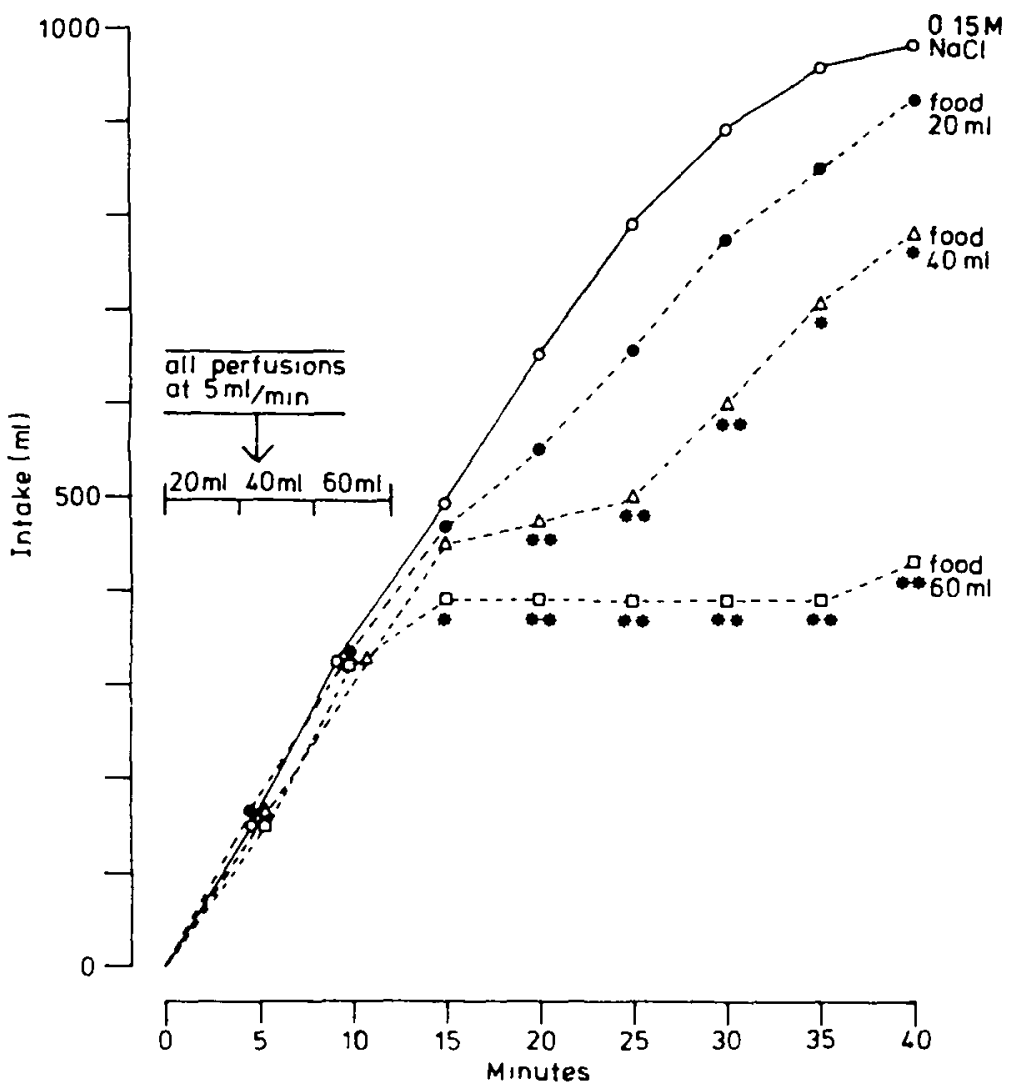

Figure 5 Cumulatıve liquid food intakes in all tests when gastric cannulas were open and the small intestine was infused with different volumes of liquid food (dashed lines) or equivolumetric $.15 \mathrm{M} \mathrm{NaCl}$ (continuous line). (Since there was no discernible difference between the three saline controls, these have been combined for the purpose of clarity of illustration; for statistical purposes, however, each food volume was compared with the appropriate equivolummetric saline control Statistically significant differences from salıne controls. ${ }^{*} p<05,{ }^{* *} p<.01$, matched-pairs $t$ test, two-talled)

tion of this cessation varied from animal to animal. In addition, once sham feeding had begun again in each animal, the vigor with which it was sustained varied from animal to animal.

Figure 5 demonstrates that the satiety effect noted in Figure 4 is dose-related. As the volume of intestinally infused food increased, the extent and duration of satiety increased. The $20-\mathrm{ml}$ volume did not significantly suppress sham intake, whereas the $40-\mathrm{ml}$ volume produced a statistically significant suppression from the 20 -min point onward. Recovery of the original rapid rate of sham feeding is clearly seen after the 40-ml volume. In contrast, the satiety effect of the $60-\mathrm{ml}$ volume was much more prolonged, and recovery of sham feeding did not occur during the test period. The threshold volume of food required to produce satiety, $40 \mathrm{ml}$, is a relatively small one, amounting to approximately $15 \%$ of the total meal size of monkeys when they eat normally (i.e., with both cannulas closed) under these conditions of diet and deprivation.

The behaviors exhibited by monkeys following duodenal infusions were of interest. When each monkey stopped sham feeding, it characteristically exhibited the same sequence of satiety behaviors that we had previously observed in Experiments 1,2, and 3 during those occasions when the animals ate normally with gastric cannulas closed. This behavioral sequence consisted of the cessation of feeding, a brief period of grooming of the arms and upper torso, visual exploration of the test cubicle, and apparent sleep. After this period of behavioral tran- 
quilization, each monkey awakened suddenly and began to sham feed again.

Two interesting characteristics of the unidentified satiety signals that are activated by duodenal food in this experiment are worthy of note. First, the signals are potent, since a small volume of food in the small intestine was sufficient not only to stop sham feeding but to elicit the complete and characteristic behavioral display of satiety. (Even though the volume infused was relatively small-about $15 \%$ of normal meal size-it is nevertheless important to note that the present results do not establish the physiological relevance of this phenomenon; we have not compared the amount of food that normally empties from the stomach under these experimental conditions with the amount required to stop sham feeding and elicit behavioral satiety.) A second characteristic is that these signals do not require the presence of gastric distention to operate, since gastric distention cannot occur when monkeys sham feed with gastric cannulas open.

An examination of Figure 4 reveals one further behavioral feature of this experiment which is of interest. In each animal, note that the duodenal food infusion ends well before sham feeding stops. This characteristic delay between the end of the stimulus and the behavioral response ranged in duration from 4 to $8 \mathrm{~min}$. During this delay period, which was always present, the monkeys continued to sham feed vigorously, even though the duodenal infusion had ended. We believe this delay is important for two reasons. First, it provides strong evidence that the monkeys are not made acutely uncomfortable by the duodenal infusion procedure. Second, the occurrence of this delay strongly suggests that the unidentified satiety signal demonstrated here is humoral and not neural in nature. It is not possible to decide, on the basis of the present results, whether this humoral signal is of preabsorptive or postabsorptive origin.

These results demonstrate that food delivered directly to the small intestine is sufficient to stop sham feeding and elicit the behavioral sequence of satiety. Thus, in rhesus monkeys, as in rats (Liebling, Eisner, Gibbs, \& Smith, 1975), a potent satiety signal, which can operate independently of gastric distention, arises at the level of the small intestine.

\section{General Discussion}

At which anatomical sites in the gastrointestinal tract does food provide necessary and/or sufficient stimuli for satiety? The series of experiments reported here examined this question in rhesus monkeys. The experiments have demonstrated the following: (a) When food does not accumulate in the stomach or enter the small intestine, satiety is absent. Therefore, pregastric food stimuli are not sufficient to produce normal-sized meals. (b) Liquid food enters the small intestine almost immediately upon ingestion. Therefore, the intestine is a candidate as a site of origin of satiety signals. (c) If ingested food is removed as it enters the small intestine, food intake is doubled. Therefore, the accumulation of food in the small intestine is necessary to produce normal-sized meals. (d) A small amount of food placed directly in the small intestine is sufficient to elicit the full behavioral display of satiety in sham-feeding animals, in the absence of gastric distention. Therefore, a potent preabsorptive or postabsorptive satiety signal originates at the intestine. Thus, these results direct attention to the potency of satiety signals that arise at the level of the intestine.

These experiments do not exclude a satiety role for the stomach. Several studies using rats have provided strong evidence that important satiety signals originate at the gastric level.. Davis and Campbell (1973) used a gastric aspiration technique to remove half of an ingested milk diet at various times after feeding began. They found that rats resumed eating within approximately $3 \mathrm{~min}$ of the time of aspiration from the stomach and that the volume of milk ingested was very close to the volume removed. They also investigated the accuracy of this satiety mechanism by aspirating a wide range of different volumes from the stomach $20 \mathrm{~min}$ after feeding began. The milk intake over the next $30 \mathrm{~min}$ was strikingly close to the volume removed (Davis \& Campbell, 1973). We also examined the effect of draining stomach contents after a meal of liquid food had been ingested in overnight-deprived 
rats, and we found that all rats began to eat within 10 to $30 \mathrm{~min}$ (Young et al., 1974). Furthermore, in preliminary observations on three of the four monkeys studied in the present report, we observed that draining all gastric contents immediately after the end of a control test meal (both cannulas closed) resulted in a resumption of feeding with short latency. This observation suggests that gastric stimulation soon after the end of a meal is a factor in limiting further food intake. In addition, we noted that as the time between the end of the meal and the drainage of gastric contents increased, the latency to resume feeding also increased. This correlation strongly suggests that other factors-intestinal or postabsorptive events-become more important than gastric stimulation with time.

Removal of stomach contents, however, does more than simply decrease gastric distention. It also slows gastric emptying, which in turn would diminish any satiety mechanisms activated by food entering the intestine. In order to eliminate the possibility of intestinal satiety, two groups (Deutsch, Young, \& Kalogeris, 1978; Kraly \& Smith, 1978) used techniques to prevent gastric emptying at a test meal. After implantation of a chronic pyloric noose (which completely prevented gastric emptying when it was drawn tight), rats ate the same-size meal and displayed the normal behavioral sequence of satiety whether the pyloric noose was open or closed (Kraly \& Smith, 1978); we have since confirmed this result and demonstrated that this gastric satiety effect does not depend upon an intact vagal innervation to the stomach (Kraly \& Gibbs, 1980). Deutsch et al. employed a more sophisticated arrangement which not only prevented gastric emptying but also relieved excessive intragastric pressure that might follow pyloric occlusion; their results also demonstrated that food intake was very similar whether ingested food was allowed to enter the small intestine or not.

A conflict emerges from a comparison of the results in the rat and the results of the present experiments in the rhesus monkey. Kraly and Smith, and Deutsch et al., demonstrated that the rat stomach is sufficient to control meal size- that food does not have to stimulate intestinal receptors to provide this function. On the other hand, in Experiment 3 , we demonstrated that food must accumulate in the small intestine of the rhesus monkey in order for meal size to be controlled at normal levels.

In addition to the possibility of a species difference, one explanation for this apparent conflict is that a large amount of redundancy exists in the control systems governing satiety, so that either the stomach or the intestine is sufficient to produce a cessation of feeding. Another possible explanation is that the stomach and intestine normally interact to produce satiety and that the rate of gastric emptying serves as a link between these two anatomical areas. It is well known that stimuli in the small intestine act to slow gastric emptying (Hunt, 1956, 1961). One might postulate a chain of events initiated by the accumulation of food in the small intestine, which would act to slow gastric emptying, with the resulting accumulation of food and gastric distention signaling satiety through as yet unidentified routes. This is, in fact, a mechanism that has recently been proposed, based on the demonstration that glucose emptied from the stomach affects food intake only when the stomach is distended (McHugh, 1979).

According to this model, the stomach would be sufficient for satiety in the rat studies of Kraly and Smith (1978) and Deutsch et al. (1978) because an artificial method of limiting gastric emptying was employed, replacing the intestinal mechanism that would normally accomplish this purpose. Our present Experiment 3 is also consistent with this model: When food is removed from the intestine, gastric emptying would be accelerated, gastric contents would be significantly diminished, and the normal gastric satiety signals would be unactivated or less activated, with the result that food intake would increase.

Nevertheless, this economical model relating the two factors of intestinal satiety and gastric emptying is not a complete explanation, because Experiments 1 and 4 clearly dissociate the two: In Experiment 1 , when gastric emptying is fast via open gastric cannulas, feeding is also fast; in Experiment 4 , when gastric emptying is equally fast via open gastric cannulas in the same animals but food is placed directly into the 
small intestine, feeding stops and the complete behavioral sequence of satiety occurs. Furthermore, cholecystokinin, an intestinal hormone and putative satiety signal that is known to decrease gastric emptying, still operates effectively to suppress feeding when gastric cannulas are open (Gibbs, Young, \& Smith, 1973a), and secretin, an intestinal hormone that inhibits gastric emptying, fails to suppress food intake in intact rats feeding normally, even in large doses (Gibbs, Young, \& Smith, 1973b).

We conclude that identification of a single anatomical site of origin of satiety signals from the gastrointestinal tract is unlikely. The results of the present study direct attention to the function of the small intestine as one region that is important in satiety, but they do not exclude a satiety role for the stomach. How the intestine and stomach act independently and in concert to contribute to satiety is the goal of current work.

\section{Reference Note}

1 Gibbs, J., \& Falasco, J. D. Unpublished observations, 1976.

\section{References}

Baile, C. A., Zınn, W., \& Mayer, J. Feeding behavior of monkeys. Glucose utilization rate and site of glucose entry Physiology and Behavior, 1971, 6, $531-537$

Beaumont, W. Experiments and observations on the gastric juice and physiology of digestion New YorkDover Press, 1959 (Originally published, 1833.)

Campbell, C.S., \& Davis, J D Licking rate of rats is reduced by intraduodenal and intraportal glucose infusion. Phystology and Behavior, 1974, 12, 357-365

Chaddock, T. E., Carlson, G. M , \& Hamilton, C. L. Gastric emptying of a nutritıonally balanced hquid diet in the rhesus monkey. In E. E. Daniel (Ed.), Proceedings of the Fourth International Symposium on Gastrointestinal Motility Vancouver: Mitchell Press, 1974

Davis, J. D., \& Campbell, C S. Peripheral control of meal size in the rat: Effect of sham feeding on meal size and drinking rate. Journal of Comparative and Phy'siological Psychology, 1973, 83, 379-387.

Dethier, V G., \& Bodenstenn, D. Hunger in the blowfly Zettschrift für Tıerpsychologte, 1958, 15, 129-140.

Dethier, V. G, \& Gelperin, A. Hyperphagia in the blowfly. Journal of Experimental Biology, 1967, 47, 191-200.

Deutsch, J. A., Young, W G., \& Kalogeris, T. J. The stomach signals satiety Sctence, 1978, 201, 165-167
Dubois, A., Natelson, B. H., van Eerdewegh, P., \& Gardner, J. D. Gastric emptying and secretion in the rhesus monkey. American Journal of Physiology; 1977, 232, E186-E192.

Ehman, G. K., Albert, D. J., \& Jamieson, J. L. Injections into the duodenum and the induction of satiety in the rat. Canadian Journal of Psychology, 1971, $25,147-166$.

Gibbs, J., \& Falasco, J. D. Sham feeding in the rhesus monkey. Physiology and Behavior, 1978, 20, 245-249.

Gıbbs, J., Young, R. C., \& Smith, G. P. Cholecystokinin elicits satiety in rats with open gastric fistula. $\mathrm{Na}$. ture, 1973, 245, 323-325. (a)

Gibbs, J, Young, R. C., \& Smith, G. P. Cholecystokinın inhibits food intake in rats. Journal of Comparatwe and Physiological Psychology, 1973, 84, 488-495. (b)

Hill, R G., Ison, E C , Jones, W. W., \& Archdeacon, J $W$ The small intestine as a factor in the regulation of eating. American Journal of Physiology, 1952. $170,201-205$.

Hull, C L., Livingston, J. R., Rouse, R. O., \& Barker, A N. True, sham, and esophageal feeding as rein forcements. Journal of Comparative and Physio logical Psychology, 1951, 44, 236-245.

Hunt, J. N. Some properties of an alimentary osmo receptor mechanism. Journal of Physiology, 1956 . $132,267-288$.

Hunt, J. N. The osmotic control of gastric emptying Gastroenterology', 1961, 41, 49-51

James, W. T. An analysis of esophageal feeding as a form of operant reinforcement in the dog. Psycho. logıcal Reports, 1963, 12, 13-39.

Janowitz, H. D., \& Grossman, M. I. Some factors affecting the food intake of normal dogs and dogs with esophagostomy and gastric fistula American Journal of Phystology, 1949, 159, 143-148.

Jordan, H. A Voluntary intragastric feeding: Oral and gastric contributions to food intake and hunger in man. Journal of Comparative and Physiologicai Psychology, 1969, 68, 498-506.

Kısch, B. Jacob Helm's observations and experıments on human digestion. Journal of the History of Medicine, 1954, 9, 311-328.

Kraly, F. S., \& Gibbs, J. Vagotomy fails to block the satiating effect of food in the stomach. Physiolog: and Behavior, 1980, 24, 1007-1010.

Kraly, F.S., \& Smith, G P Combined pregastric and gastric stimulation by food is sufficient for normal meal size. Physiology and Behavior, 1978, 21 $405-408$.

Liebling, D. S, Eisner, J., Gibbs, J., \& Smith, G P Intestinal satiety in rats. Journal of Comparatus and Physiological Psychology, 1975, 89, 955-965

Maddrell, S. H. P. Control of ingestion in Rhodniu prolixus Stal. Nature, 1963, 198, 210.

McHugh, P. R. Aspects of the control of feeding Application of quantitation in psychobiology. The Johns Hopkins Medical Journal, 1979, 144 147-155.

McHugh, P. R., \& Moran, T. H. Calories and gastric emptying: A regulatory capacity with implications for feeding American Journal of Physiology, 1979 236, R254-R260.

McHugh, P. R., Moran, T. H., \& Barton, G. N. Satiet 
A graded behavioral phenomenon regulating caloric intake. Scuence, 1975, 190, 167-169.

Novin, D, Sanderson, J. D., \& VanderWeele, D. A. The effect of isotonic glucose on eating as a function of feeding condition and infusion site. Physiology and Behavıor, 1974, 13, 3-7

Nuñez, J. A. Trinktriebregelung bei insekten. Naturwissenschaften, 1964, 17, 419.

Quartermain, D., Kissıleff, H., Shapiro, R., \& Miller, N E. Suppression of food intake with intragastric loading: Relation to natural feeding cycle. Sctence, 1971, 173, 941-943.

Snowdon, C T Production of satsety with small in- traduodenal infusions in the rat. Journal of Comparative and Physialogıcal Psy'chology', 1975, 88, 231-238.

Wilson, M J., Dickson, W H., \& Singleton, A C Rate of evacuation of various foods from the normal stomach Archives of Internal Medicine, 1929, 44, $787-796$.

Young, R. C, Gıbbs, J , Antin, J., Holt, J., \& Smith, G $P$. Absence of satiety during sham feeding in the rat. Journal of Comparative and Physiological Psychology, 1974, 87, 795-800.

Received January 12, 1981 